\title{
Shoe Box Product Development Design Based on Consumer Preference
}

\section{Rancangan Pengembangan Produk Kotak Sepatu Berdasarkan Preferensi Konsumen}

\author{
Rossi Septy Wahyuni', Eko Nursubiyantoro², Kristiyani Dwi Agustin ${ }^{1}$ \\ ${ }^{1}$ Jurusan Teknik Industri, Fakultas Teknologi Industri \\ Universitas Gunadarma, Jalan Margonda Raya No 100, Pondok Cina, Depok, 16424 \\ 2 Jurusan Teknik Industri, Fakultas Teknik Industri \\ Universitas Pembangunan Nasional "Veteran" Yogyakarta, Jalan Babarsari no. 2 Tambakbayan, Yogyakarta \\ 55181 \\ email : rossysw@staff.gunadarma.ac.id,kristiyanidaa@gmail.com \\ doi: https://doi.org/10.31315/opsi.v14i1.4500
}

Received: $17^{\text {th }}$ February 2021; Revised: $2^{\text {th }}$ March 2021; Accepted: $16^{\text {th }}$ April 2021;

Available online: 24 ${ }^{\text {th }}$ June 2021; Published regularly: June 2021

\begin{abstract}
Climate change which is triggered by a consumptive human culture continues to be a concern for many parties to be tackled. Shoes have become the primary need of urban communities because of their function that cannot be separated from their daily activities. Shoes that are purchased by consumers are usually packaged in cardboard boxes that follow the components of the contents, namely the shoes and accessories inside. In this case, shoeboxes with the right design and function according to consumer preferences will reduce the likelihood that the shoeboxes are thrown into the trash. Although it is not the centre of consumer attention, shoe boxes remain a necessity in the final production process. It is necessary to design and develop a shoebox product that is in accordance with the final function of the shoebox according to consumer interests. This study uses the QFD method which produces quality 1 houses with communication tools in the form of a preliminary questionnaire to 30 respondents and a follow-up questionnaire to 100 respondents. Concept selection was carried out on the eight alternative concepts developed. The shoebox concept chosen to take into account the desires of the consumer will be made with a sporty shoebox standard size of $22.5 \times 12.3 \times 32.5 \mathrm{~cm}$. The environmentally friendly shoebox can be seen through the installation of plastic straps which are expected to reduce the use of single-use plastics. In addition, the shoebox is made with an innovative design so that users can use it repeatedly as shoe storage or multipurpose box.
\end{abstract}

Keywords: $Q F D, H O Q$, consumer, shoe box, concept selection

\begin{abstract}
ABSTRAK
Perubahan iklim yang dipicu oleh budaya konsumtif manusia terus menjadi perhatian banyak pihak untuk ditanggulangi. Sepatu sudah menjadi kebutuhan primer masyarakat perkotaan karena fungsinya yang tidak lepas dari kegiatan sehari-hari. Sepatu yang dibeli konsumen biasanya dikemas dalam kotak kardus yang mengikuti komponen isinya yaitu sepatu dan aksesoris di dalamnya. Dalam hal ini kotak kardus sepatu dengan rancangan yang tepat dan dapat berfungsi sesuai dengan keinginan konsumen akan mengurangi kemungkinan kotak sepatu tersebut dibuang menjadi sampah. Walaupun tidak menjadi pusat perhatian konsumen, kotak sepatu tetap menjadi kebutuhan proses akhir produksi yaitu pengemasan sepatu. Perlu perancangan dan pengembanan produk kotak sepatu yang sesuai dengan fungsi akhir kotak sepatu sesuai dengan minat konsumen. Penelitian ini menggunakan metode QFD yang menghasilkan rumah kualitas 1 dengan alat komunikasi berupa kuesioner pendahuluan kepada 30 responden dan kuesioner lanjutan pada 100 responden. Pemilihan konsep dilakukan pada delapan konsep alternatif yang dikembangkan. Konsep kotak sepatu yang terpilih dengan mempertimbangkan keinginan konsumen akan dibuat dengan ukuran standar kotak sepatu sporty yaitu 22,5x 12,3 x 32,5 cm. Kotak sepatu yang ramah lingkungan dapat dilihat melalui pemasangan tali plastik yang diharapkan dapat mengurangi penggunaan plastik sekali pakai. Selain itu kotak sepatu dibuat dengan desain
\end{abstract}


yang inovatif agar pengguna dapat menggunakannya berulang kali sebagai penyimpan sepatu atau kotak serbaguna.

Kata Kunci: $Q F D, H O Q$, konsumen, kotak sepatu, pemilihan konsep

\section{PENDAHULUAN}

Pendekatan yang dapat dilakukan untuk membuat produk yang sesuai dengan keinginan konsumen salah satunya adalah dengan menggunakan metode Quality Function Deployment ( $Q F D$ ). Maksud dari penggunaan Quality Function Deployment (QFD) adalah menentukan produk yang memuaskan konsumen pada aspek yang beragam dan mewujudkannya dalam bentuk target rancangan (Akao, 1990). Quality Function Deployment (QFD) digunakan pada proses awal design untuk memuaskan keinginan konsumen sehingga produk dapat ditawarkan di pasaran dengan kualitas yang mumpuni. Penggunaan metode Quality Function Deployment (QFD) dianggap tepat karena memudahkan dalam pengolahan data berupa kualitatif menjadi kuntitatif, sehingga keinginan konsumen dapat diwujudkan dengan proses penelitian yang efektif.

Penelitian ini bertujuan memberikan usulan rancangan produk kotak sepatu dengan penggunaan akhir yang optimal sehingga ramah lingkungan sesuai dengan kebutuhan konsumen.

Masalah dalam inovasi kotak sepatu adalah bagaimana desain produk kotak sepatu yang ramah lingkungan dan dapat dimanfaatkan secara optimal berdasarkan penggunaan akhir yang memuaskan konsumen. Masalah tersebut menjadi pertimbangan untuk dilakukannya perancangan inovasi kotak sepatu sesuai kebutuhan konsumen.

\section{METODE}

\subsection{Pengembangan Produk}

Proses pengembangan produk yang dilakukan dengan baik dapat berguna untuk menjamin kualitas produk, menjaga koordinasi tim, proses perencanaan, manajemen dalam identifikasi masalah, dan mengidentifikasi peluang perbaikan. Kesimpulan dari proses pengembangan produk adalah pengadaan produk yang dapat dibeli di pasar. Enam fase dari proses pengembangan produk ditunjukkan pada Gambar 1 (Ulrich \& Eppinger, 2012).

Perencanaan produk mengidentifikasi berbagai rancangan produk yang akan dikembangkan oleh perusahaan dan waktu yang tepat untuk pengenalan produk ke pasar. Proses perencanaan mempertimbangkan peluang dari pengembangan produk yang diidentifikasi melalui banyak sumber, termasuk dari pemasaran, penelitian, pelanggan, tim pengembangan produk, dan benchmarking pesaing. Dari antara peluang-peluang ini, portofolio proyek dipilih, penentuan waktu proyek diuraikan, dan sumber daya dialokasikan. Lima langkah dalam proses perencanaan produk ditunjukkan pada Gambar 2 (Ulrich \& Eppinger, 2012).

Proses mengidentifikasi kebutuhan pelanggan merupakan bagian integral dari proses pengembangan produk yang lebih besar dan erat terkait dengan pembuatan konsep, pemilihan konsep, persaingan kompetitif, dan pembentukan spesifikasi produk. Mengidentifikasi kebutuhan pelanggan dilakukan untuk perbaikan yang berkelanjutan bagi perusahaan. Tahapan identifikasi kebutuhan pelanggan yaitu mengumpulkan data mentah dari pelanggan, menginterpretasikan data mentah menjadi kebutuhan pelanggan, mengorganisasikan kebutuhan pelanggan menjadi beberapa hierarki, menetapkan derajat kebutuhan relatif setiap kebutuhan pelanggan, dan menganalisa hasil dan proses (Ulrich \& Eppinger, 2012).

Proses penyusunan konsep dimulai dengan satu set kebutuhan pelanggan dan spesifikasi target sehingga menghasilkan serangkaian konsep produk yang kemudian akan ditentukan pilihan akhir oleh tim. merupakan lima tahap penyusunan konsep (Ulrich \& Eppinger, 2012).

Integrasi masalah arus logistik dalam sistem desain proses pada umumnya bukan lagi menjadi pilihan karena lingkungan yang sangat kompetitif dan menyusutnya basis sumber daya mengarahkan keterlibatan hal tersebut.

Masalah dukungan sistem harus ditangani sejak awal selama proses definisi kebutuhan dan berkembang secara progresif melalui fase desain sistem berikutnya. Metode Quality Function Deployment (QFD) menawarkan kerangka kerja yang diperlukan untuk mencapai tujuan ini. Potensi manfaat yang 


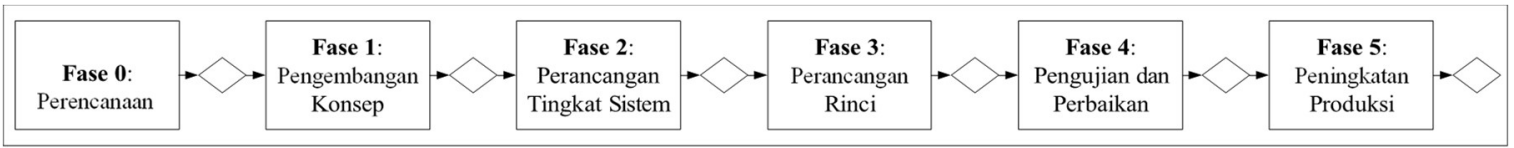

Gambar 1. Fase Pengembangan Produk (Sumber: Ulrich \& Eppinger, 2012)

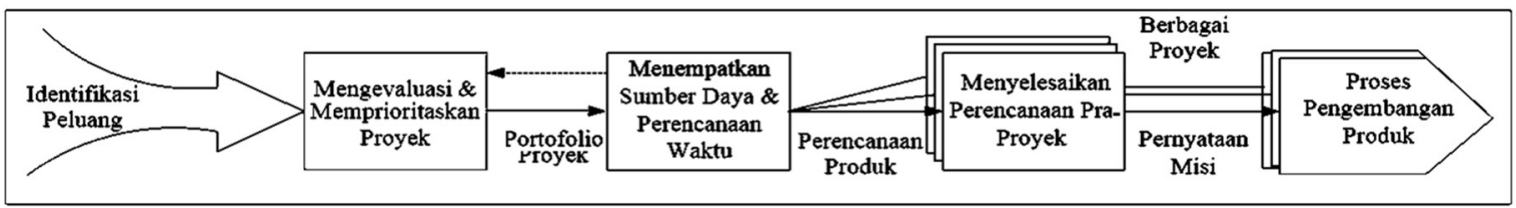

Gambar 2. Proses Perencanaan Produk (Sumber: Ulrich \& Eppinger, 2012)

didapatkan dengan menggunakan Quality Function Deployment (QFD) yaitu pengembangan produk yang berfokus pada pelanggan, siklus pengembangan sistem yang lebih pendek, peningkatan efisiensi desain sistem awal, pertukaran desain sistem awal yang efektif, dan lebih sedikit masalah untuk memulai produksi (Verma dkk, 1995).

\subsection{Quality Function Deployment (QFD)}

Quality Function Deployment (QFD) tidak selalu mudah diimplementasikan, dan perusahaan menghadapi masalah dalam menggunakan Quality Function Deployment $(Q F D)$, terutama dalam sistem yang besar dan kompleks. Masalah dalam implementasi Quality Function Deployment (QFD) dikategorikan dalam tiga kelompok sebagai masalah metodologis, masalah organisasi, dan masalah tentang kebijakan produk.

Masalah yang sering muncul dalam implementasi Quality Function Deployment (QFD) yaitu jika semua matriks relasional

Tabel 1. Alasan dan Faktor Penentu Jumlah Sampel

\begin{tabular}{|c|c|c|}
\hline No. & Faktor & Alasan \\
\hline 1. & Representasi & $\begin{array}{l}\text { Galat (error) } \\
\text { sampel, keakuratan } \\
\text { data }\end{array}$ \\
\hline 2. & $\begin{array}{l}\text { Pertimbangan } \\
\text { sumber dana, } \\
\text { waktu, dan } \\
\text { personil }\end{array}$ & $\begin{array}{l}\text { Keterbatasan dana } \\
\text { dan peralatan }\end{array}$ \\
\hline 3. & $\begin{array}{l}\text { Keseragaman } \\
\text { populasi }\end{array}$ & $\begin{array}{l}\text { Nilai-nilai dalam } \\
\text { masyarakat }\end{array}$ \\
\hline 4. & Metode analisis & $\begin{array}{l}\text { Persyaratan yang } \\
\text { dibutuhkan }\end{array}$ \\
\hline 5. & $\begin{array}{l}\text { Persyaratan } \\
\text { instrumentasi } \\
\text { stastistika } \\
\text { lainnya }\end{array}$ & $\begin{array}{l}\text { Kepercayaan } \\
\text { interval,tingkat } \\
\text { kepercayaan }\end{array}$ \\
\hline
\end{tabular}

digabungkan menjadi satu penempatan maka ukuran masing-masing matriks relasional gabungan akan sangat besar, $Q F D$ adalah metode kualitatif sehingga banyak jawaban yang diberikan pelanggan sulit untuk dikategorikan sebagai permintaan, mungkin sulit untuk menentukan hubungan antara permintaan pelanggan dan peralatan mekanis yang ada sehingga organisasi tidak memperpanjang penggunaan QFD pada tahap perencanaan produk, dan QFD tidak sesuai untuk semua aplikasi (Shahla, 2013).

Matriks rumah kualitas (house of quality) paling dikenal dan banyak digunakan untuk mencapai kepuasan pelanggan yang lebih tinggi. Rumah kualitas adalah peta konseptual yang menyediakan sarana untuk perencanaan dan komunikasi antar fungsional. Rumah kualitas memungkinkan manajer organisasi untuk melakukan penilaian pesaing dari perspektif pelanggan. Alasan digunakannya

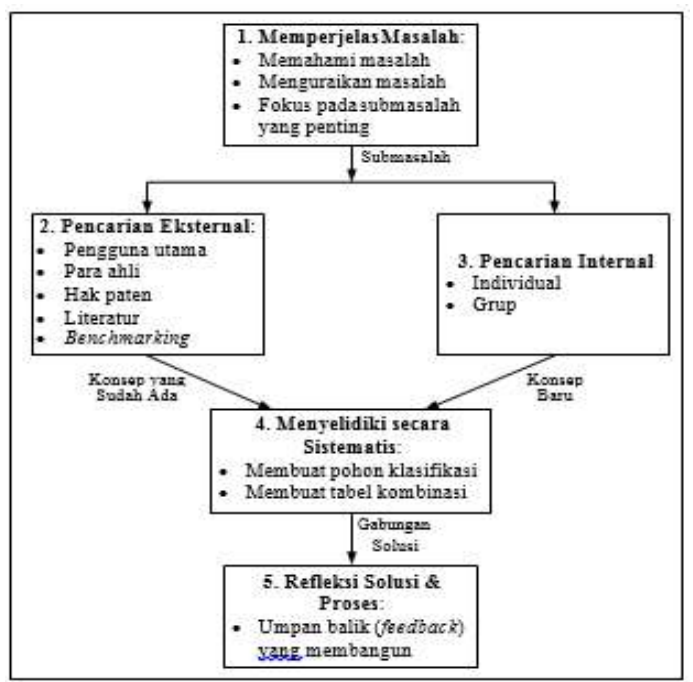

Gambar 3. Tahap Penyusunan Konsep (Sumber: Ulrich \& Eppinger, 2012) 
rumah kualitas di bidang industri adalah munculnya faktor-faktor sebagai berikut; kompleksitas pengembangan produk, perpanjangan waktu pengembangan, adanya keluhan dari konsumen akan produk atau jasa yang diberikan, kurang efisien dan efektifnya tim pengembangan produk atau proses, turunnya pangsa pasar secara konsisten, kurangnya struktur untuk alokasi sumber daya pengembangan produk (Shrivastava, 2013). Sebelum melakukan pengumpulan data yang perlu diperhatikan adalah jenis data apa yang dibutuhkan dalam penelitian. Secara ideal, apabila $100 \%$ populasi dijadikan sampel maka akan sangat bagus dan sangat representif untuk dilakukan uji. Namun, keterbatasan dana, waktu dan komplesitas pengumpulan data, maka dibutuhkan pengambilan sampel. Berikut merupakan rekomendasi faktor-faktor yang perlu dipertimbangkan dalam menentukan ukuran sampel (David \& Djamaris, 2018).

Pemilihan konsep adalah proses mengevaluasi konsep berdasarkan kebutuhan pelanggan dan kriteria lainnya, membandingkan kekuatan dan kelemahan relatif dari konsep, dan memilih satu atau lebih konsep untuk penyelidikan, pengujian, atau pengembangan lebih lanjut. Terlepas dari apakah proses pemilihan konsep eksplisit atau tidak, semua tim menggunakan beberapa metode untuk memilih di antara konsep. Macam-macam metode pemilihan konsep dengan tingkat keefektifannya masing-masing adalah keputusan eksternal, produk juara, intuisi, multivoting, survey berbasis web, pro dan kontra, prototype dan pengujian, dan matriks keputusan (Ulrich \& Eppinger, 2012).

Penyaringan konsep didasarkan pada metode yang dikembangkan oleh almarhum Stuart Pugh pada 1980-an dan sering disebut pemilihan konsep Pugh (Pugh, 1990). Tujuan tahap ini adalah mempersempit jumlah konsep dengan cepat dan menyempurnakan konsep. Penyaringan konsep dilakukan melalui enam tahap yaitu siapkan seleksi matriks, beri nilai untuk tiap konsep, ranking konsep berdasarkan nilai, gabungkan dan tingkatkan konsep, pilih satu atau lebih konsep, dan refleksikan hasil dan proses penyaringan konsep (Ulrich \& Eppinger, 2012).

Identifikasi masalah dilakukan sebagai dasar dilakukannya penelitian. Masalah yang ditemukan akan dipertimbangkan agar menemukan pemecahan masalah dengan solusi yang tepat berdasarkan metode-metode tertentu. Setelah masalah terindentifikasi, diperlukan studi literatur yang dapat diperoleh melalui penelitian terdahulu dan landasan teori yang bersangkutan dengan penelitian.

Tujuan penelitian ditetapkan agar penelitian berjalan pada arah yang tepat dan mendapatkan solusi yang bermanfaat. Selanjutnya dilakukan penyusunan kuesioner untuk memperoleh data primer dari konsumen secara langsung. Kuesioner yang disusun dengan skala likert disebarkan pada responden dengan kriteria tertentu.

Data yang digunakan dalam penelitian ini merupakan data primer yang didapatkan melalui kuesioner. Kuesioner diadaptasi melalui kuesioner yang pernah disebarkan pada penelitian sebelumnya dengan modifikasi karakteristik produk sesuai dengan penelitian terhadap kebutuhan kotak sepatu. Data primer diperoleh untuk mengetahui penggunaan akhir kotak sepatu oleh konsumen. Atribut produk kotak sepatu yang ada di pasaran merupakan data primer yang didapatkan dari kuesioner kebutuhan konsumen. Produk kotak sepatu yang ada di pasaran merupakan acuan penelitian untuk mendapatkan gambaran ukuran dan spesifikasi produk pada umumnya sehingga data sekunder juga didapatkan untuk penelitian ini. Berdasarkan informasi kebutuhan konsumen dari produk kotak sepatu yang ada di pasaran, dilakukan penelitian lanjutan untuk menentukan inovasi yang diperlukan pada kotak sepatu yang akan dirancang.

Pengumpulan data dilakukan dengan metode kuesioner tertutup yang disebarkan melalui Google Form kepada responden yang pernah membeli sepatu dengan kemasan kotak kardus. Penyebaran dan pengisian kuesioner secara online dapat menghemat waktu dan biaya penelitian serta memudahkan responden dalam melakukan pengisian karena dapat dilakukan melalui handphone dan dapat diakses dimana saja.

Data atribut produk yang didapatkan dari responden diuji validitas dan realibilitasnya sebelum kemudian diolah pada tahap selanjutnya. Uji validitas dan reliabilitas dilakukan dengan bantuan sofware, jika data yang didapatkan sudah valid dan reliabel, 
maka atribut-atribut produk kotak sepatu tersebut dapat digunakan untuk perancangan dan pengembangan produk kotak sepatu.

Berdasarkan keinginan konsumen, akan dibuat matriks rumah kualitas untuk mengetahui nilai bobot kepentingan dari setiap karakteristik teknis. Bobot kepentingan tersebut nantinya akan menentukan prioritas perbaikan pada produk kotak sepatu berdasarkan nilai bobot tertinggi hingga terendah. Dari beberapa karakteristik yang dapat dikembangkan kemudian dibuat beberapa konsep yang sesuai dengan keinginan konsumen. Berdasarkan kriteria tertentu kemudian satu konsep dipilih untuk diterapkan dalam perancangan dan pengembangan produk kotak sepatu.

\section{HASIL DAN PEMBAHASAN}

Penelitian awal telah dilakukan dengan mengumpulkan data kuesioner dari 30 responden, sehingga menghasilkan tujuh atribut utama yang menggambarkan keinginan konsumen terhadap kotak sepatu. Tujuh atribut tersebut kemudian diteliti lebih lanjut dengan kuisioner terhadap 100 responden menggunakan skala likert satu hingga lima. Hasil dari 100 responden yang mengisi kuesioner penelitian ini, merupakan masyarakat umum yang menggunakan kotak sepatu. Data perolehan dari kuesioner diuji realibilitas dan validitasnya untuk diproses lebih lanjut. Kuesioner yang disebarkan berisi pernyataan setuju hingga tidak setuju mengenai produk kotak sepatu. Tabel 2 berikut merupakan hasil uji validitas dan uji reliabilitas untuk tujuh atribut pada kuesioner penelitian.

Seluruh atribut produk memiliki tingkat kepentingan diatas 3 sehingga dapat disimpulkan ketujuh atribut produk penting. Tujuh atribut kotak sepatu yaitu kotak sepatu yang berfungsi sebagai penyimpan sepatu atau kotak serbaguna, memiliki tali, memiliki sekat pemisah antaraksesoris, kotak sepatu dengan dasar matte berwarna, berukuran cukup sesuai, memiliki matrial yang kuat, dan memiliki desain yang menarik dan fungsional. Tabel 3 berikut merupakan tabel tingkat kepentingan atribut kotak sepatu.

Kegiatan mengidentifikasi kebutuhan konsumen merupakan hal yang mengawali pembuatan house of quality atau rumah kualitas. Identifikasi kebutuhan konsumen dilakukan melalui penyebaran kuesioner

Tabel 2. Hasil Uji Validitas dan Uji Reliabilitas

\begin{tabular}{|c|c|c|c|c|c|}
\hline No. & Atribut & $N V$ & Ket. & $N R$ & Ket. \\
\hline 1. & $\begin{array}{l}\text { Kotak kardus } \\
\text { sepatu berfungsi } \\
\text { sebagai } \\
\text { penyimpan sepatu } \\
\text { atau kotak } \\
\text { serbaguna }\end{array}$ & 0,782 & Valid & 0,766 & Reliabel \\
\hline 2. & $\begin{array}{l}\text { Kotak kardus } \\
\text { sepatu memiliki } \\
\text { tali agar mudah } \\
\text { dibawa }\end{array}$ & 0,661 & Valid & 0,796 & Reliabel \\
\hline 3. & $\begin{array}{l}\text { Kotak kardus } \\
\text { sepatu memiliki } \\
\text { sekat pemisah } \\
\text { antar aksesoris }\end{array}$ & 0,710 & Valid & 0,788 & Reliabel \\
\hline 4. & $\begin{array}{l}\text { Kotak kardus } \\
\text { sepatu dengan } \\
\text { dasar matte warna }\end{array}$ & 0,649 & Valid & 0,802 & Reliabel \\
\hline 5. & $\begin{array}{l}\text { Kotak kardus } \\
\text { sepatu berukuran } \\
\text { cukup sesuai } \\
\text { dengan sepatu } \\
\text { yang dikemas }\end{array}$ & 0,564 & Valid & 0,813 & Reliabel \\
\hline 6. & $\begin{array}{l}\text { Kotak kardus } \\
\text { sepatu berbahan } \\
\text { dasar material } \\
\text { yang kuat }\end{array}$ & 0,733 & Valid & 0,777 & Reliabel \\
\hline 7. & $\begin{array}{l}\text { Kotak kardus } \\
\text { sepatu memiliki } \\
\text { desain yang } \\
\text { menarik dan } \\
\text { fungsional }\end{array}$ & 0,749 & Valid & 0,775 & Reliabel \\
\hline
\end{tabular}

$N V$ : Nilai Validitas

NR : Nilai Reliable

Tabel 3. Tingkat Kepentingan Atribut Kotak

\begin{tabular}{clc}
\multicolumn{1}{c}{ Sepatu } \\
\hline No. & \multicolumn{1}{c}{ Atribut } & \multicolumn{1}{c}{$\begin{array}{c}\text { Tingkat } \\
\text { Kepentingan }\end{array}$} \\
\hline 1. & $\begin{array}{l}\text { Kotak kardus sepatu berfungsi } \\
\text { sebagai penyimpan sepatu atau } \\
\text { kotak serbaguna }\end{array}$ & 4,16 \\
2. & $\begin{array}{l}\text { Kotak kardus sepatu memiliki tali } \\
\text { agar } \\
\text { mudah dibawa }\end{array}$ & 3,88 \\
3. $\begin{array}{l}\text { Kotak kardus sepatu memiliki sekat } \\
\text { pemisah antaraksesoris }\end{array}$ & 3,67 \\
4. $\begin{array}{l}\text { Kotak kardus sepatu dengan dasar } \\
\text { matte dengan warna }\end{array}$ & 3,59 \\
5. $\begin{array}{l}\text { Kotak kardus sepatu berukuran } \\
\text { cukup } \\
\text { sesuai dengan sepatu yang dikemas }\end{array}$ & 4,34 \\
Kotak kardus sepatu berbahan dasar \\
material yang kuat
\end{tabular}


penelitian. Penyebaran kuesioner dilakukan dengan dua tahap, yaitu kuesioner pendahuluan pada 30 responden dan kuesioner lanjutan pada 100 responden. Lalu data yang dihasilkan dari kuesioner penelitian tersebut menghasilkan atribut kotak sepatu yang penting untuk meningkatkan kepuasan konsumen. Dari atribut kotak sepatu tersebut, dilakukan penentuan hubungan teknik.

Penentuan hubungan teknik dapat dilakukan dengan studi literatur mengenai kotak sepatu referensi agar kotak sepatu yang dirancang tidak menyimpang dari fungsi yang sebenarnya. Tabel 4 merupakan hubungan teknik setiap atribut kotak sepatu.

Setelah data-data yang diperlukan memenuhi untuk dibuat dalam bentuk rumah kualitas, maka rumah kualitas dibuat dengan menggunakan software QFD (Quality Function Deployment). Rumah kualitas nantinya akan membantu dalam pengembangan kotak sepatu inovasi yang sesuai dengan keinginan konsumen. Gambar 4 berikut merupakan rumah kualitas (house of quality) dari kotak sepatu.

Karakteristik teknik yang akan dikembangkan memiliki uraian penjelasan berdasarkan atribut kotak sepatu, keluhan

Tabel 4. Hubungan Teknik Atribut Kotak Sepatu

\begin{tabular}{|c|c|c|}
\hline No. & Atribut & Hubungan Teknik \\
\hline \multirow[t]{3}{*}{1.} & \multirow{3}{*}{$\begin{array}{l}\text { Kotak kardus sepatu berfungsi } \\
\text { sebagai penyimpan sepatu atau } \\
\text { kotak serbaguna }\end{array}$} & Fungsional \\
\hline & & Inovatif \\
\hline & & Kapasitas \\
\hline \multirow[t]{2}{*}{2.} & \multirow{2}{*}{$\begin{array}{l}\text { Kotak kardus sepatu memiliki tali } \\
\text { agar mudah dibawa }\end{array}$} & Inovatif \\
\hline & & Ergonomis \\
\hline \multirow[t]{2}{*}{3.} & \multirow{2}{*}{$\begin{array}{l}\text { Kotak kardus sepatu memiliki } \\
\text { sekat pemisah antaraksesoris }\end{array}$} & Inovatif \\
\hline & & Kapasitas \\
\hline \multirow[t]{2}{*}{4.} & \multirow{2}{*}{$\begin{array}{l}\text { Kotak kardus sepatu dengan } \\
\text { dasar matte dengan warna }\end{array}$} & Inovatif \\
\hline & & Bahan baku utama \\
\hline \multirow[t]{3}{*}{5.} & \multirow{3}{*}{$\begin{array}{l}\text { Kotak kardus sepatu berukuran } \\
\text { cukup sesuai dengan sepatu yang } \\
\text { dikemas }\end{array}$} & Ergonomis \\
\hline & & Bahan baku utama \\
\hline & & Kapasitas \\
\hline \multirow[t]{2}{*}{6.} & \multirow{2}{*}{$\begin{array}{l}\text { Kotak kardus sepatu berbahan } \\
\text { dasar material yang kuat }\end{array}$} & Bahan baku utama \\
\hline & & Kapasitas \\
\hline \multirow[t]{2}{*}{7.} & \multirow{2}{*}{$\begin{array}{l}\text { Kotak kardus sepatu memiliki } \\
\text { desain yang menarik dan } \\
\text { fungsional }\end{array}$} & Inovatif \\
\hline & & Fungsional \\
\hline
\end{tabular}

konsumen, dan saran perbaikan dari konsumen. Uraian ini berguna sebagai acuan pengembangan kotak sepatu berdasarkan keinginan konsumen. Tabel 5 berikut merupakan tabel solusi pengembangan kotak sepatu.

Tabel 5. Solusi Pengembangan Kotak Sepatu

\begin{tabular}{|c|c|c|c|}
\hline No. & Atribut & Keluhan & Solusi \\
\hline 1. & $\begin{array}{l}\text { Kotak kardus } \\
\text { sepatu berfungsi } \\
\text { sebagai } \\
\text { penyimpan } \\
\text { sepatu atau } \\
\text { kotak serbaguna }\end{array}$ & $\begin{array}{l}\text { Kotak sepatu } \\
\text { mudah rusak dan } \\
\text { pengait antar } \\
\text { bagian kardus } \\
\text { mudah lepas }\end{array}$ & $\begin{array}{l}\text { Kotak sepatu } \\
\text { dibuat lebih } \\
\text { kuat dan } \\
\text { sesuai dengan } \\
\text { fungsi } \\
\text { utamanya }\end{array}$ \\
\hline 2. & $\begin{array}{l}\text { Kotak kardus } \\
\text { sepatu memiliki } \\
\text { tali agar mudah } \\
\text { dibawa }\end{array}$ & $\begin{array}{l}\text { Kotak sepatu } \\
\text { seringkali } \\
\text { diberikan } \\
\text { bersamaan dengan } \\
\text { kantong plastik } \\
\text { kepada konsumen, } \\
\text { sehingga tidak } \\
\text { ramah lingkungan }\end{array}$ & $\begin{array}{l}\text { Kotak sepatu } \\
\text { memiliki tali } \\
\text { agar mudah } \\
\text { dibawa }\end{array}$ \\
\hline 3. & $\begin{array}{l}\text { Kotak kardus } \\
\text { sepatu memiliki } \\
\text { sekat pemisah } \\
\text { antaraksesoris }\end{array}$ & $\begin{array}{l}\text { Aksesoris dapat } \\
\text { mengubah bentuk } \\
\text { sepatu jika } \\
\text { diletakkan } \\
\text { bersamaan }\end{array}$ & $\begin{array}{l}\text { Kotak sepatu } \\
\text { dibuat } \\
\text { dengan } \\
\text { tempat } \\
\text { aksesoris } \\
\text { khusus }\end{array}$ \\
\hline 4. & $\begin{array}{l}\text { Kotak kardus } \\
\text { sepatu dengan } \\
\text { dasar matte } \\
\text { dengan warna }\end{array}$ & $\begin{array}{l}\text { Kotak sepatu tanpa } \\
\text { warna tidak } \\
\text { menarik untuk } \\
\text { dijadikan } \\
\text { penyimpan } \\
\text { sepatu jangka } \\
\text { panjang }\end{array}$ & $\begin{array}{l}\text { Kotak sepatu } \\
\text { dibuat } \\
\text { menarik } \\
\text { dengan warna } \\
\text { matte }\end{array}$ \\
\hline 5. & $\begin{array}{l}\text { Kotak kardus } \\
\text { sepatu berukuran } \\
\text { cukup sesuai } \\
\text { dengan sepatu } \\
\text { yang dikemas }\end{array}$ & $\begin{array}{l}\text { Kotak sepatu yang } \\
\text { terlalu kecil tidak } \\
\text { fleksibel untuk } \\
\text { konsumen } \\
\text { meletakkan sepatu } \\
\text { dengan berbagai } \\
\text { posisi di dalam } \\
\text { kotak }\end{array}$ & $\begin{array}{l}\text { Ukuran kotak } \\
\text { sepatu } \\
\text { disesuaikan } \\
\text { dengan isi } \\
\text { yang dimuat } \\
\text { di dalamnya }\end{array}$ \\
\hline 6. & $\begin{array}{l}\text { Kotak kardus } \\
\text { sepatu berbahan } \\
\text { dasar material } \\
\text { yang kuat }\end{array}$ & $\begin{array}{l}\text { Kotak sepatu } \\
\text { mudah rusak } \\
\text { sehingga tidak } \\
\text { memenuhi } \\
\text { fungsinya pada } \\
\text { jangka waktu } \\
\text { tertentu }\end{array}$ & $\begin{array}{l}\text { Kota sepatu } \\
\text { menggunakan } \\
\text { bahan dasar } \\
\text { yang kuat }\end{array}$ \\
\hline 7. & $\begin{array}{l}\text { Kotak kardus } \\
\text { sepatu memiliki } \\
\text { desain yang } \\
\text { menarik dan } \\
\text { fungsional }\end{array}$ & $\begin{array}{l}\text { Kotak sepatu tidak } \\
\text { menarik untuk } \\
\text { digunakan sebagai } \\
\text { penyimpan sepatu } \\
\text { untuk jangka } \\
\text { panjang }\end{array}$ & $\begin{array}{l}\text { Desain kotak } \\
\text { sepatu dibuat } \\
\text { menarik dan } \\
\text { sesuai fungsi } \\
\text { utama }\end{array}$ \\
\hline
\end{tabular}

Ketujuh atribut primer yang masingmasing kemudian memiliki solusi berdasarkan keluhan konsumen akan didekomposisikan menjadi masalah primer, sekunder dan tersier untuk didapatkan konsep-konsep yang dapat dikembangkan disajikan dalam Tabel 6 yang merupakan tabel dekomposisi masalah. Dari dekomposisi masalah yang diuraikan tersebut, kemudian dapat dibuat konsep-konsep pengembangan produk kotak sepatu.

Berdasarkan kombinasi atribut tersier, akan didapatkan delapan konsep produk 
Tabel 6. Dekomposisi Masalah

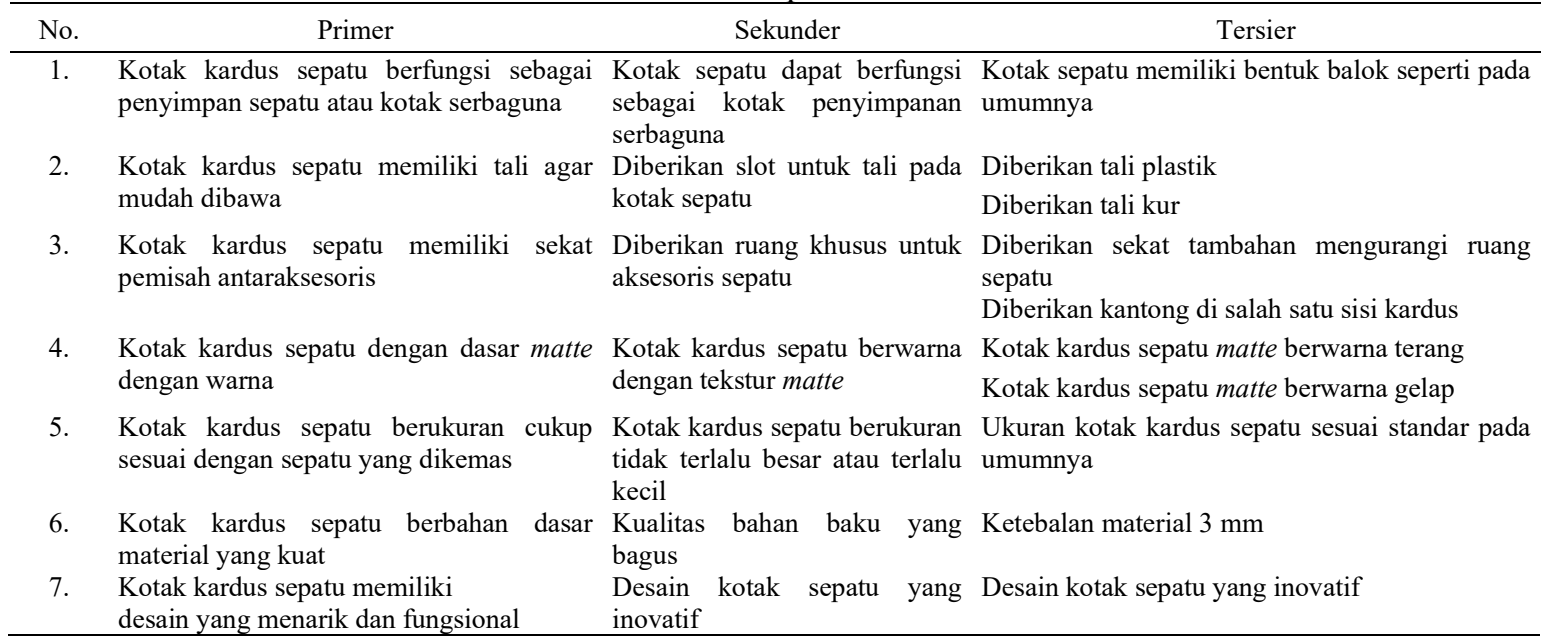

Tabel 7. Pengembangan Konsep Produk

\begin{tabular}{|c|c|c|c|c|c|c|c|}
\hline Konsep & A1 & $\mathrm{A} 2$ & A3 & A4 & A5 & A6 & A7 \\
\hline $\mathrm{A}$ & Berbentuk balok & Tali plastik & $\begin{array}{l}\text { Sekat pemisah } \\
\text { aksesoris }\end{array}$ & $\begin{array}{l}\text { Matte berwarna } \\
\text { terang }\end{array}$ & Ukuran standar & $\begin{array}{l}\text { Ketebalan } \\
3 \mathrm{~mm}\end{array}$ & $\begin{array}{l}\text { Desain } \\
\text { inovatif }\end{array}$ \\
\hline $\mathrm{B}$ & Berbentuk balok & Tali kur & $\begin{array}{l}\text { Sekat pemisah } \\
\text { aksesoris }\end{array}$ & $\begin{array}{l}\text { Matte berwarna } \\
\text { terang }\end{array}$ & Ukuran standar & $\begin{array}{l}\text { Ketebalan } \\
3 \mathrm{~mm}\end{array}$ & $\begin{array}{l}\text { Desain } \\
\text { inovatif }\end{array}$ \\
\hline $\mathrm{C}$ & Berbentuk balok & Tali plastik & Kantong aksesoris & $\begin{array}{l}\text { Matte berwarna } \\
\text { terang }\end{array}$ & Ukuran standar & $\begin{array}{l}\text { Ketebalan } \\
3 \mathrm{~mm}\end{array}$ & $\begin{array}{l}\text { Desain } \\
\text { inovatif }\end{array}$ \\
\hline $\mathrm{D}$ & Berbentuk balok & Tali kur & Kantong aksesoris & $\begin{array}{l}\text { Matte berwarna } \\
\text { terang }\end{array}$ & Ukuran standar & $\begin{array}{l}\text { Ketebalan } \\
3 \mathrm{~mm}\end{array}$ & $\begin{array}{l}\text { Desain } \\
\text { inovatif }\end{array}$ \\
\hline $\mathrm{F}$ & Berbentuk balok & Tali kur & $\begin{array}{l}\text { Sekat pemisah } \\
\text { aksesoris }\end{array}$ & $\begin{array}{l}\text { Matte berwarna } \\
\text { gelap }\end{array}$ & Ukuran standar & $\begin{array}{l}\text { Ketebalan } \\
3 \mathrm{~mm}\end{array}$ & $\begin{array}{l}\text { Desain } \\
\text { inovatif }\end{array}$ \\
\hline G & Berbentuk balok & Tali plastik & Kantong aksesoris & $\begin{array}{l}\text { Matte berwarna } \\
\text { gelap }\end{array}$ & Ukuran standar & $\begin{array}{l}\text { Ketebalan } \\
3 \mathrm{~mm}\end{array}$ & $\begin{array}{l}\text { Desain } \\
\text { inovatif }\end{array}$ \\
\hline
\end{tabular}

Tabel 8. Pemilihan Konsep Kotak Sepatu

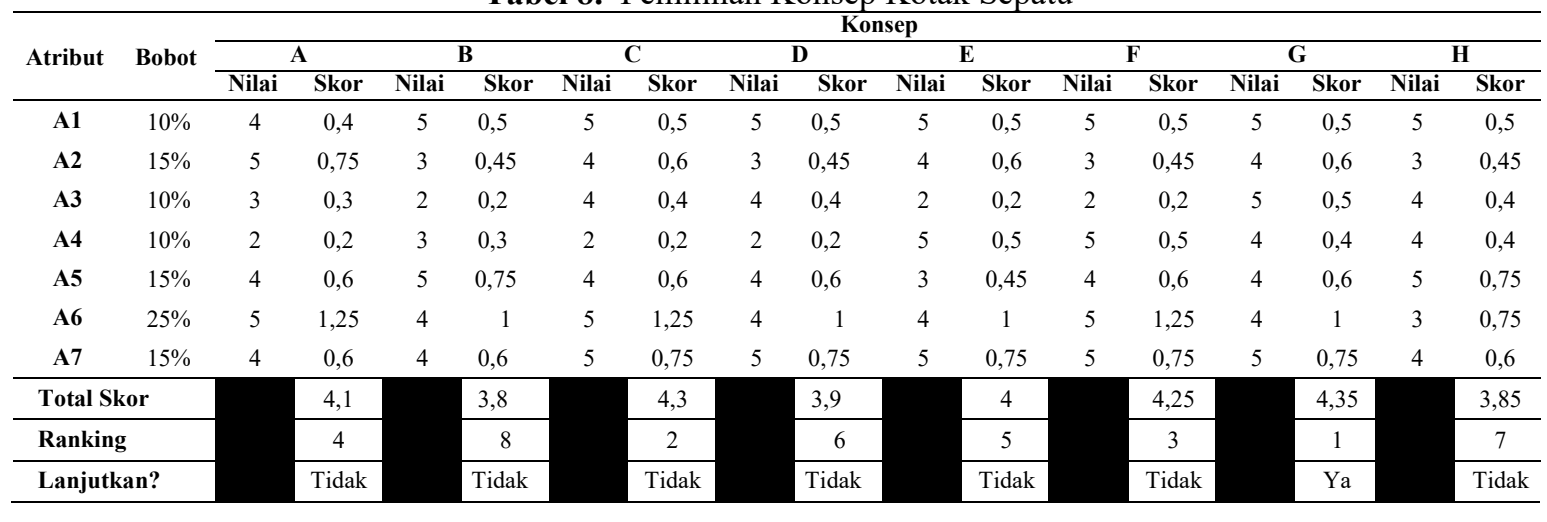

sebagaimana ditampilkan pada Tabel 7 . Kedelapan konsep akan dipilih satu untuk menjadi produk inovasi kotak sepatu. Pemilihan konsep dilakukan dengan mengevaluasi kelebihan dan kelemahan tiap atribut dari alternatif yang ditetapkan. Tiap atribut diberikan bobot dan tiap konsep diberikan skor berdasarkan kemampuannya memenuhi atribut yang bersangkutan. Konsep dengan total skor tertinggi kemudian dipilih sebagai konsep yang dapat dilanjutkan pada proses pengembangan.

Tabel 8 berikut ini merupakan tabel pemilihan konsep kotak sepatu inovasi, 


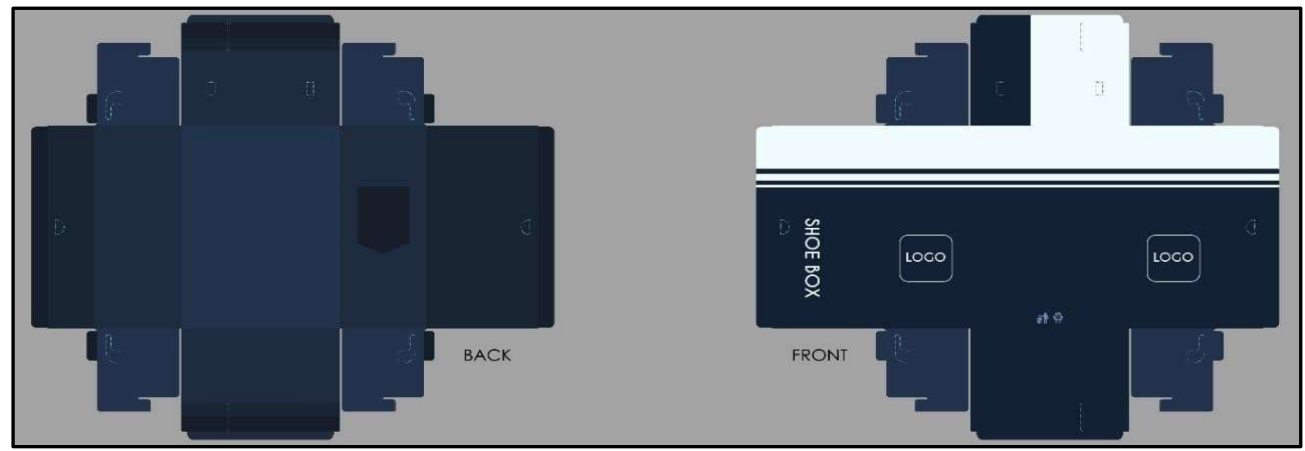

Gambar 5. Layout Kotak Sepatu

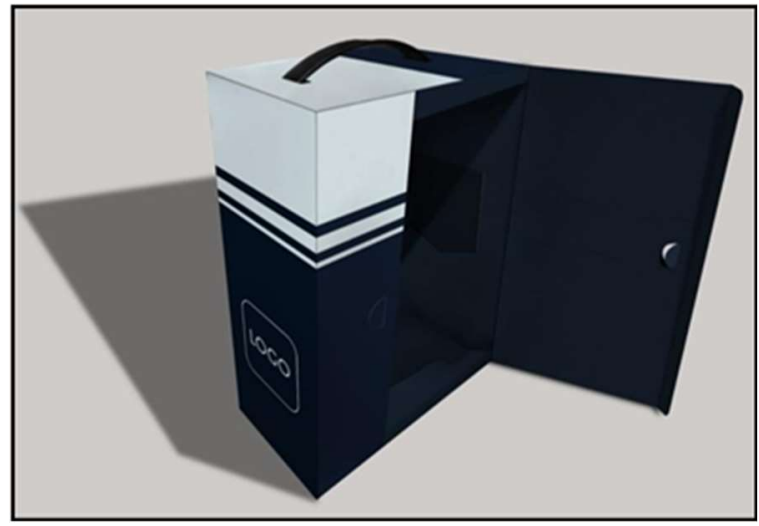

Gambar 6. Prototype 3D Kotak Sepatu
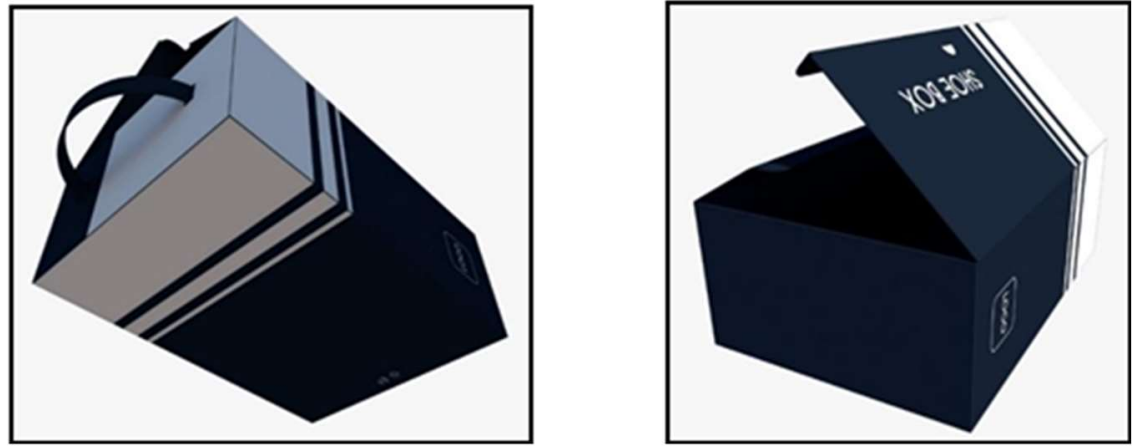

Gambar 7. Prototype 3D Kotak Sepatu

desain produk kotak sepatu dengan tampilan layout dibuat menggunakan software desain grafis ditampilkan tampak depan dan belakang pada Gambar 5, Gambar 6 dan Gambar 7.

\section{KESIMPULAN}

Kesimpulan dari penelitian ini adalah hasil rancangan desain kotak sepatu berdasarkan preferensi konsumen yaitu berbentuk balok, tali dari plastik, kantong aksesoris, matte berwarna gelap, ukuran standar, ketebalan $3 \mathrm{~mm}$ dengan desain yang inovatif.
Saran yang dapat diberikan oleh peneliti adalah perlunya edukasi konsumen dan produsen agar beralih ke material produk ramah lingkungan, dan meminimasi penggunaan material non ramah lingkungan. Penelitian lebih lanjut agar dapat menggali lebih dalam preferensi konsumen dengan jenis material produk ramah konsumen dan data konsumen berdasarkan katagori usia.

\section{DAFTAR PUSTAKA}

Akao, Y. (1990). QFD : Integratisng Costumer Requirement into Product Design. 
Productifity Press, Cambridge. Massachusetts.

Curcic, Srecko dan Sida Milunovic (2007). Product Development Using Quality Function Deployment (QFD). International Journal for Quality research, Vol. 1 (3), 243-247.

David, Wahyudi dan Aurino R. A. Djamaris. (2018). Metode Statistik Untuk Ilmu dan Teknologi Pangan. Jakarta: Penerbitan Universitas Bakrie.

Heizer, Jay dan Barry Render. (2011). Operations Management. New Jersey: Pearson Education.

Irawan, Agustinus Purna. (2017). Perancangan dan Pengembangan Produk Manufaktur. Yogakarta: Penerbit ANDI.

Mehrjerdi, (2009). Quality function deployment and its extensions. International Journal of Quality \& Reliability Management (IJQRM), Vol. 27 (6), 616-640. DOI $10.1108 / 02656711011054524$.

Multyaningsih, Endang. (2011). Riset Terapan Bidang Pendidikan dan Teknik. Yogyakarta: UNY Press.
Shahla, Raed Abu. (2013). Polyethylene Terephthalate (PET) Preform Design: A Quality Function Deployment (QFD) Approach [Tesis]. Gaza (PLE): The Islamic University - Gaza.

Shrivastava, Praveen (2016). House of Quality: An Effective Approach to Achieve Customer Satisfaction \& Business Growth in Industries. International Journal of Science and Research (IJSR), Vol. 5, 1365-1371.

Ulrich, Karl T. dan Steven G. Eppinger. (2012). Product Design and Development Fifth Edition. New York: Mc-Grow Hill.

Verma, Dinesh, Rajesh Chilakapati, dan Benjamin S. Blanchard (1995). Quality Function Deployment (QFD): Integration Of Logistics Requirements Into Mainstream System Design. Jurnal dari Systems Engineering Design Laboratory (SEDL) Industrial and Systems Engineering Virginia Tech Blacksburg. DOI: 10.1.1.488.4851 